\title{
Strengthening of Masonry Arch Bridges with Near-Surface Reinforcement: A Case Study
}

\author{
S. W. Garrity
}

\begin{abstract}
The rehabilitation of a single span clay brick arch highway bridge is described. The bridge, which dates from 1798 , is located in Southern England and spans an inland waterway. Operational constraints and the historic importance of the bridge required the use of a minimum intervention, minimum disruption form of strengthening. Near-surface reinforcement was chosen to meet these requirements. This paper describes the design philosophy and the installation of the longitudinal, transverse and inter-ring dowel reinforcement.
\end{abstract}

Index Terms—Arches, brickwork, masonry, strengthening.

\section{INTRODUCTION}

Hungerford Canal Bridge is a grade II listed single span clay brick arch structure dating from circa 1798. It has a clear span of approximately $7.1 \mathrm{~m}$ measured between the exposed faces of the brickwork abutments. The $330 \mathrm{~mm}$ thick arch barrel has an elliptical profile and a maximum rise of $2.35 \mathrm{~m}$; it supports fill with an average depth of $460 \mathrm{~mm}$ at the crown. The wingwalls, pilasters, spandrel walls and parapets are all of solid brickwork construction. The grade II listing means that the bridge has been included on a statutory list of structures in England that are designated to be of special architectural or historical interest "which warrant every effort being made to preserve them" [1].

The bridge carries the busy A338 public highway across the Kennet and Avon Canal and is located in the county of Berkshire in Southern England, UK. The highway is one of the main links between the small town of Hungerford and the regional M4 motorway which connects London and South Wales. Although the canal fell into disrepair and many sections of it were closed by the 1950s, with the formation of British Waterways Board in 1962 the canal was gradually restored and was re-opened fully to traffic in 2003. It is now used extensively by tourists who not only use the waterway but also walk or cycle along its towpath. The canal is also used by a small amount of commercial traffic.

An assessment of the load carrying capacity of the bridge indicated that it was in need of strengthening to meet current operating standards. In addition, many parts of the exposed brickwork were found to be suffering from frost damage and needed to be replaced. The consulting engineer appointed by

Manuscript received February 15, 2013; revised April 8, 2013. The research that underpinned the development of the strengthening measures described in this paper was supported by Bersche-Rolt Limited, Uckfield, East Sussex, England, UK. Bersche-Rolt were the designers and specialist contractors for the Hungerford Canal Bridge rehabilitation project.

S. W. Garrity is with the Institute of Resilient Infrastructure at the School of Civil Engineering, University of Leeds, Leeds, West Yorkshire, England, UK (e-mail: s.w.garrity@leeds.ac.uk). the bridge owner to investigate alternative strengthening methods selected near-surface reinforcement because the highway could remain open to traffic at all times and there would be minimal disruption to the residential properties and small businesses located close to the bridge, the nearest being approximately $5 \mathrm{~m}$ away from one of the wingwalls. In addition, the contractor proposed to drill into the brickwork and install all the reinforcement from a working platform floating on the canal. By temporarily suspending construction operations and moving the floating working platform away from the bridge, canal traffic could pass beneath it. A more detailed evaluation of the alternative forms of strengthening considered by the client's consulting engineer is described by McKibbins et al. [2].

\section{Design Philosophy: StRENGTHENING WORKS}

With masonry arch bridges and similar structures, any strengthening measures that are designed solely to increase strength are unlikely to represent good value for money. Exposure to longer-term risks to the continued well-being of the bridge such as differential settlement, localised scour and increased weathering effects should also be considered by the designer as well as the need to minimise any disruption to the bridge users and local people. Taking into account these requirements and the listed status of the bridge, it was considered essential to design the strengthening works for Hungerford Canal Bridge to:

1). Increase the load-carrying capacity of the arch barrel to meet modern operational requirements defined by the UK Highways Agency;

2). Minimise any disruption to the canal users, the highway users, local residents and businesses;

3). Minimise the risk of any future damage to or deterioration of the bridge caused by the strengthening works;

4). Integrate increased robustness, durability and resilience into the design;

5). Respect the architectural and historical heritage of the bridge.

Near-surface reinforcement (also known as retro-reinforcement) was developed as a minimum disruption, minimum intervention strengthening technique for masonry arch bridges [3] - [6] with the aforementioned requirements. It involves the installation of low corrosion risk reinforcing bars, usually between $6 \mathrm{~mm}$ and $16 \mathrm{~mm}$ in diameter, into grooves or holes that have been previously cut or drilled into the readily accessible surfaces of the bridge where tensile stresses are likely to occur. Usually stainless steel reinforcement is used because it is much more ductile than carbon or glass fiber reinforced polymer alternatives. 
Typically reinforcing bars are installed in the intrados (or soffit) of the arch barrel and the exposed faces of the piers, abutments, spandrels, parapets and wingwalls. The principal aims of adding such reinforcement are to improve flexural crack control, increase flexural and shear strength and to increase robustness and ductility without causing a marked change in the structural behavior. Research [7] - [11] has confirmed that these aims can be achieved with comparatively small amounts of reinforcement. In particular, in a series of tests on sixteen $3 \mathrm{~m}$ span clay brick arches conducted in the laboratory [11], longitudinal reinforcement was found to increase the load carrying capacity by at least $43 \%$. There was no evidence of premature de-bonding failure of the reinforcement or the grout. Radial inter-ring dowel reinforcement was also found to be an effective means of avoiding premature failure as a result of inter-ring shear.

\section{REINFORCEMENT DESIGN AND INSTALLATION}

\section{A. Design Principles}

For Hungerford Canal Bridge the design requirements described previously were satisfied by installing an array of comparatively small diameter stainless steel reinforcing bars in the longitudinal and transverse directions in the arch barrel. Radial inter-ring dowel reinforcement was also provided to minimise the risk of premature failure due to ring separation. As mentioned previously, all the reinforcement was installed from a working platform supported on pontoons in the canal, as shown in Fig. 1.

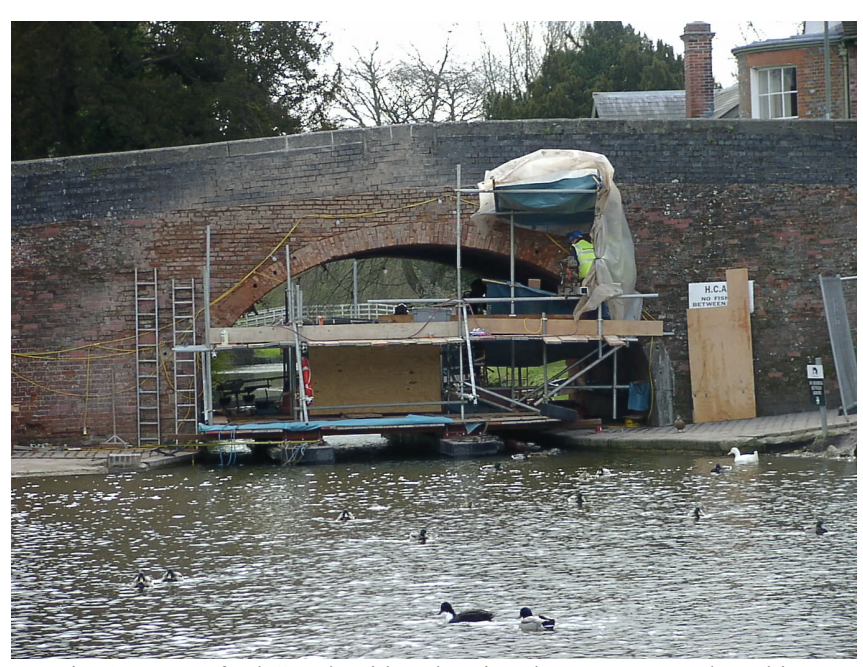

Fig. 1. Hungerford Canal Bridge showing the pontoons and working platform.

The distance between adjacent reinforcing bars was kept in the range $300 \mathrm{~mm}$ to $400 \mathrm{~mm}$ to reduce the likelihood of overstressing the original brickwork and to produce, in effect, a mesh of reinforcement. This can be regarded in a similar vein to the crack control and distribution steel provided in most reinforced concrete slabs. In addition, radial dowels were installed through the full thickness of the arch barrel to reduce the risk of ring separation. The installation of the transverse, longitudinal and radial dowel reinforcement is described briefly, below.

The longitudinal (main) reinforcement was designed using a limit state approach with partial factors of safety and loads defined by the UK Highways Agency [12]. The critical bending moments used in the structural design were obtained from a plastic analysis of the arch barrel. The analysis was based on the 4-hinge mechanism method first proposed by Heyman [13] for unreinforced arches subjected to a line load representing the axle of a vehicle. In the author's experience, with short span masonry arch bridges it is usually a single axle load which tends to be critical in the design of strengthening measures rather than combinations of two or more axles where there is usually a measure of relief against sway behaviour. A 4-hinge mechanism analysis was considered to be appropriate given the observed behaviour of the arches tested in the laboratory [10], [11]. The effect of the reinforcement was taken into account in the mechanism analysis by including the moment capacity of the reinforced masonry arch barrel at the two hinges where tensile stress was expected to occur in the arch intrados (soffit). At the other two hinge locations tensile stress was expected to occur in the extrados (upper surface) where there was no reinforcement to increase the moment capacity.

In the analysis, a single vertical line load was applied to the arch barrel through the fill. Two of the hinge positions were fixed at each springing and the other two hinge positions were systematically varied to yield the lowest value of applied load. This value is defined as the collapse load by the upper bound theorem of plasticity on which the analysis was based. The amount of steel reinforcement and the moment capacity of the two hinges were increased to provide a collapse load that was at least equal to the design ultimate axle load. It should be noted that the moment capacity of an under-reinforced section was used to minimise the risk of a sudden compressive failure of the brickwork. Although the compressive strength of the brickwork of Hungerford Bridge was only of the order of $3 \mathrm{MPa}$, the arch barrel was sufficiently thick for even a fairly small area of steel reinforcement to provide a significant increase in the moment capacity of the arch barrel without risking a compression failure.

\section{B. Transverse Reinforcement}

Typically with near-surface reinforcement, stainless steel bars are grouted into pre-drilled holes across the full width of the arch barrel. This reinforcement provides improved lateral load distribution not only of concentrated wheel load effects but also any future differential settlement or loss of support from the ground due to localised scour. In the case of Hungerford Bridge, $16 \mathrm{~mm}$ diameter stainless steel reinforcing bars (fitted with wire spacers) were grouted into $50 \mathrm{~mm}$ diameter pre-drilled horizontal transverse holes centred approximately $160 \mathrm{~mm}$ above the arch intrados (or soffit). The bars were installed every $400 \mathrm{~mm}$ around the profile of the arch barrel. The drilling operation for the transverse reinforcement is shown in Fig. 2.

\section{Longitudinal Reinforcement}

Usually, such reinforcement is installed in grooves that are cut into the arch intrados using a twin-bladed circular saw. The reinforcement is subsequently bonded to the brickwork substrate using a thixotropic cementitious grout. As a result, 
strips of grout are visible on the arch intrados. With Hungerford Bridge, this was not acceptable to the bridge owners who, in keeping with the listed status of the bridge, did not want any visible evidence of the strengthening works. To accommodate this request the contractor (and the sponsor of the research described in this paper), Bersche-Rolt Limited developed a steerable flexible drive drill that could be used to drill a hole at an approximately constant depth above the intrados of the arch barrel. This now patented method was first trialled successfully in the laboratory and then used on Hungerford Bridge. For each longitudinal reinforcing bar, a $50 \mathrm{~mm}$ diameter hole was drilled centred approximately $75 \mathrm{~mm}$ above the intrados. A group of 3 no. $8 \mathrm{~mm}$ diameter stainless steel bars was threaded through the hole and grouted in place. The longitudinal steel was installed every $300 \mathrm{~mm}$ across the width of the arch barrel. To check that the drill was on course, every $4^{\text {th }}$ mortar joint was opened and the position of the drill was checked; minor adjustments to the drill position were then made where necessary. The opening up of the mortar joints was also useful as a check to ensure that the grouting operations were successful. The directional drilling operation is shown in Fig. 3.

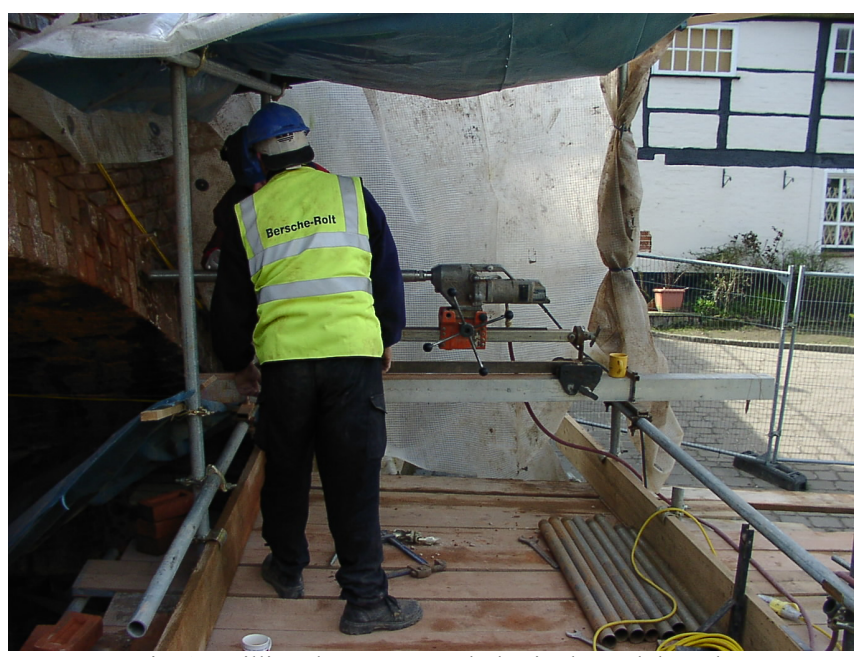

Fig. 2. Drilling the transverse holes in the arch barrel.

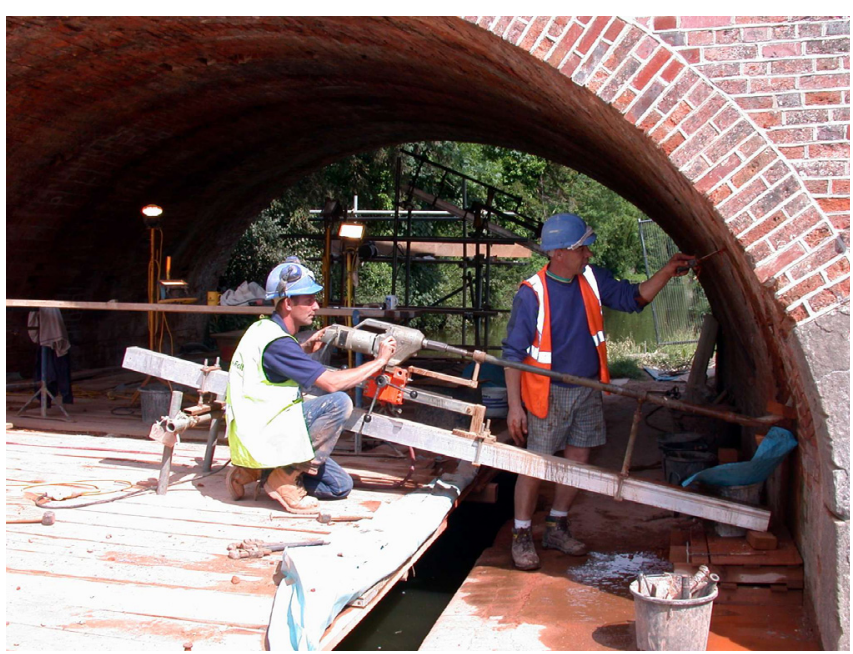

Fig. 3. Drilling the holes for the longitudinal reinforcement.

\section{Radial Dowel Shear Reinforcement}

To minimise the risk of premature longitudinal shear failure (also known as ring separation) $10 \mathrm{~mm}$ diameter stainless steel dowels were grouted every $450 \mathrm{~mm}$ into $14 \mathrm{~mm}$ diameter pre-drilled holes. A hand-held drill supported on a light tubular steel frame was used for this operation and when using equipment that could not be supported directly from the working platform or the canal towpath. This was to help minimize the risks to the health and safety of the site operatives from hand-arm vibration syndrome and other similar hazards.

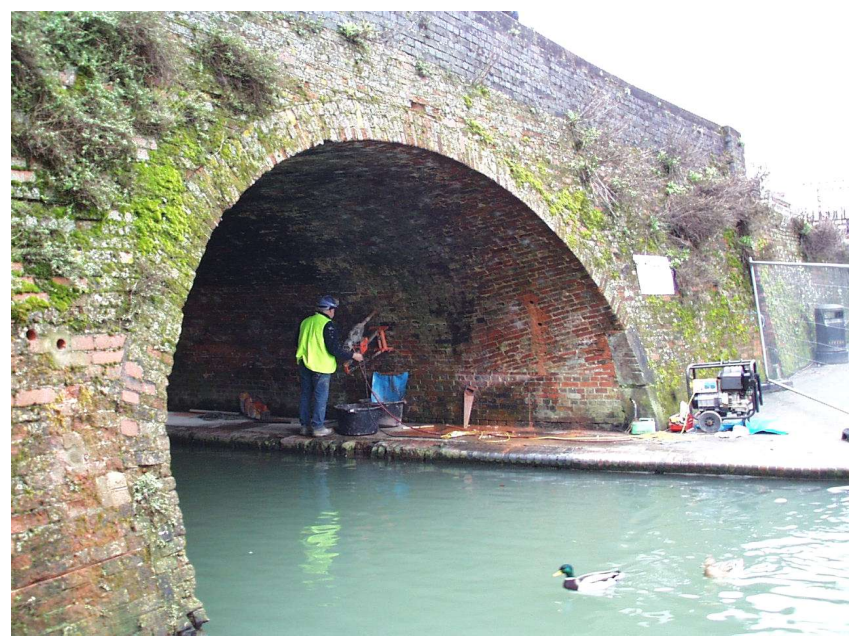

Fig. 4. Drilling the holes for the radial inter-ring dowels.

The grout used with all the reinforcement had a specified 24 hour compressive strength of $15 \mathrm{MPa}$ and a 28 day compressive strength of $40 \mathrm{MPa}$. Compliance checks were carried out by the compression testing of cube samples of the grout cured both on site and in the laboratory. All the reinforcement had characteristic tensile yield strength of 460 $\mathrm{MPa}$.

In addition to the installation of near-surface reinforcement, frost damaged bricks were replaced with new clay bricks with similar mechanical properties to the originals and the mortar joints were repointed. Fig. 5 shows a view of the completed bridge.

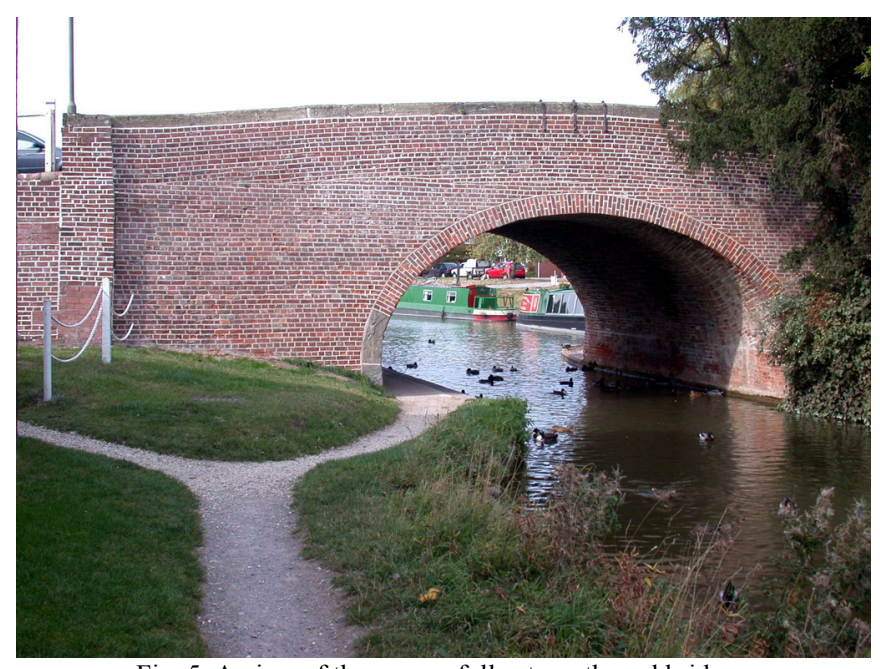

Fig. 5. A view of the successfully strengthened bridge.

\section{CONCLUSION}

The results of previous laboratory research into the behaviour of clay brick arches strengthened using near-surface reinforcement were applied to the design of the strengthening works for Hungerford Canal Bridge, a single 
span clay brick arch Highway Bridge dating from the end of the $18^{\text {th }}$ century. The strengthening measures consisted of longitudinal, transverse and radial stainless steel reinforcing bars that were grouted into pre-drilled holes to create composite action between the existing brickwork and the new reinforcement. An innovative directional drilling technique, which was developed to drill holes parallel to the arch intrados for the longitudinal reinforcing bars, proved to be very successful.

The strengthening project was judged to be successful by all concerned. The bridge manager (West Berkshire Council); owner (British Waterways); consulting engineers (Jacobs Babtie); specialist designer and contractor (Bersche-Rolt Limited) and researcher (Garrity) were collectively given a Historic Bridge and Infrastructure Award by the Institution of Civil Engineers. The judges commented that: "This is a very intrusive strengthening technique, but that is not apparent from the finished work - the concept is a clever innovation, creating minimal impact on road traffic during the works - strengthening created a bridge capable of carrying unrestricted traffic ..." [14].

\section{REFERENCES}

[1] Principles of selection for listing buildings: planning policy guidance note 15, Department for Culture, Media and Sport, Architecture and Historic Environment Division, Office of the Deputy Prime Minister, London, England, UK, 2005.

[2] L. D. McKibbins, C. Melbourne, N. Sawar, and C. Sicilia Gaillard, Masonry arch bridges: condition appraisal and remedial treatment, CIRIA Report C656, London, UK: Construction Research and Information Association, 2006.

[3] S. W. Garrity, "Retro-reinforcement of existing masonry structures," in Proc. 10th Int. Brick \& Block Masonry Conf., Calgary, Masonry Council of Canada/University of Calgary, Canada, 1994, pp. 469-478.

[4] S. W. Garrity, "Retro-reinforcement - a proposed repair system for masonry arch bridges," in Arch Bridges, C. Melbourne, Ed. London: Thomas Telford Services Ltd, 1995, pp. 557-566.

[5] J. Darby, G. Cole, S. Collins, L. Canning, S. Luke and P. Brown, Manual of Bridge Engineering: Repair, strengthening and replacement, $2^{\text {nd }}$ ed. London, UK: The Institution of Civil Engineers, 2008, p.715.

[6] M. J. Ryall, Bridge management, $1^{\text {st }}$ ed. Oxford UK: Butterworth-Heinemann, 2001, pp. 238-240.

[7] S. W. Garrity, "Testing of small scale masonry arch bridges with surface reinforcement," in Proc. 6th Int. Conf. on Structural Faults and Repair, Engineering Technics Press, Edinburgh, vol. 1, 1995, pp. 409 - 418.

[8] S. K. Sumon, "Repair and strengthening of five full scale masonry arch bridges," in Arch Bridges: history, analysis, assessment, maintenance and repair, A. Sinopoli, Ed. Balkema, Rotterdam, 1998, pp. 407-415.

[9] S. K. Sumon, "Innovative retrofitted reinforcement techniques for masonry arch bridges," in Proc. ICE, Bridge Engineering, 158, BE3, pp. 91-99, September 2005.

[10] S. W. Garrity, A. F. Ashour and Y. Chen, "An experimental investigation of retro-reinforced clay brick arches," in Proc. Int. Masonry Soc., 11, pp. 733-742, 2010.

[11] S. W. Garrity, Large-scale testing of retro-reinforced brick arches, Proc. Int. IABSE Conf, Assessment, Upgrading and Refurbishment of Infrastructures, Rotterdam, May 2013 (to be published).

[12] Design Manual for Road and Bridges (DMRB), The Highways Agency, London, UK, 2013. [Online]. Available: http://www.dft.gov.uk/ha/standards/dmrb/index.htm

[13] J. Heyman, "The estimation of the strength of masonry arches," in Proc. ICE, Pt. 2, vol. 69, pp. 921-937, December 1980.

[14] Panel for historical engineering works newsletter, ICE, London, UK, December 2004, p.3.

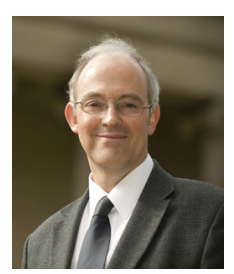

Stephen Garrity was born in England in 1956. He gained his BSc degree with first class honors in civil engineering from the University of Nottingham, UK, and his MSc degree in structural engineering from the University of Manchester, UK.

Starting as a graduate trainee with consulting engineers Sir Alexander Gibb and Partners in 1977, he gained design experience working on the Sullom Voe Terminal, Shetland and the Sea Water Cooling Project for the Jubail Industrial City in Saudi Arabia. He obtained further design and site supervision experience as a bridge engineer with Greater Manchester County Council before starting his academic career at the University of Bolton (then Bolton Institute of Higher Education) in 1984. Moving to the Department of Civil and Environmental Engineering at the University of Bradford in 1990, he served as the Head of Department from 1997 to 2002. He left in 2002 to establish his own consulting practice, Garrity Associates, but continued his link with the University of Bradford as a Visiting Professor in Civil Engineering Design. He accepted the post of Hoffman Wood Professor of Architectural Engineering at the University of Leeds in 2009. His principal research interest is structural masonry.

Prof. Garrity is a Chartered Engineer, Fellow of the Institution of Structural Engineers, Member of the Institution of Civil Engineers and a Member of the Chartered Institution of Highways and Transportation. He is also President-elect of the International Masonry Society and served as the IStructE Yorkshire Branch Chairman and Member of IStructE Council in 2003/04. He was awarded the CIHT Babtie Premium regional and national awards for a paper on masonry highway structures in 1993 and the IStructE Cass Hayward Prize for his performance in the chartered member examination in the same year. In 1994 he was awarded the IStructE's Yorkshire Branch award which led to the award of the 1994/95 Sir Arnold Waters medal. He was awarded the IStructE's Lewis Kent Award in 2007and was co-recipient of ICE's Historic Bridge and Infrastructure awards in 2004 (winner) and 2009 (commendation) for his work on two masonry arch bridge rehabilitation projects including Hungerford Canal Bridge described in this paper. 